\title{
MEDULLOEPITHELIOMA OF CILIARY BODY ADULT TYPE- A RARE PRESENTATION
}

\author{
Sharad Haribhau Shegaonkar1, Anita Madhukar Lohokare²
}

${ }_{1}^{1}$ Professor and HOD, Department of Ophthalmology, GMC, Miraj.

2 Professor and HOD, Department of Anatomy, Motherhood Ayurvedic College, Roorkee, Haridwar.

HOW TO CITE THIS ARTICLE: Shegaonkar SH, Lohokare AM. Medulloepithelioma of ciliary body adult type- a rare presentation. J. Evolution Med. Dent. Sci. 2017;6(33):2780-2784, DOI: 10.14260/Jemds/2017/599

\section{PRESENTATION OF CASE}

A 52 years old man presented with gradual, painful, progressive diminution of vision in right eye, watering and severe headache since 3 months. No other ocular complaints. His systemic history was unremarkable.

An approach to a patient with posterior segment mass with complications in the affected eye, who presented with decreased visual acuity and pain. Patient underwent ophthalmic examination. Systemic examination and investigations including complete haemogram, liver and renal function test, $\mathrm{x}$-ray chest and ultrasound abdomen were all within normal limits.

A diagnosis of posterior pole choroidal malignancy of right eye with bullous retinal detachment without any detectable metastasis with secondary glaucoma was made.

An eye that with extremely large intraocular tumour, painful and blind as a result of tumour related complications require enucleation. This patient presented with yellow subretinal mass with secondary retinal detachment. Initial diagnosis in this case was carcinoma of the choroid.

Enucleation was done with suspicion of malignant melanoma of the choroid.

Histopathology of enucleated globe showed diffuse malignant melanoma of the choroid involving posterior half. Histopathology of single right eye ball showed clinical feature suggestive of tumour mass occupying posterior chamber, firm blackish-grayish in colour.

\section{CLINICAL DIAGNOSIS}

Confirmation of clinical diagnosis of malignant medulloepithelioma of ciliary body with exact location of the tumour was made with radiological aids and correlation of pathological features was established.

\section{PATHOLOGICAL DISCUSSION}

\section{Ocular Examination}

Visual acuity in left eye was $6 / 9$ and right eye no PI. IOP in the right eye was $24.4 \mathrm{mmHg}$ and left eye was $17.3 \mathrm{mmHg}$. In the right eye ciliary tenderness was present; left eye was unremarkable.

Slit Lamp Biomicroscopy of right eye showed conjunctival congestion, cornea clear and anterior chamber depth within normal limit. No rubeosis, no cellular reaction in vitreous absence of pigmented cells in the vitreous cavity.

Financial or Other, Competing Interest: None.

Submission 14-02-2017, Peer Review 11-04-2017,

Acceptance 17-04-2017, Published 24-04-2017.

Corresponding Author:

Dr. Anita Madhukar Lohokare,

\#75, Old Subhedar Layout,

Nagpur.

E-mail: drsharadshegaonkar@gmail.com

DOI: $10.14260 /$ jemds $/ 2017 / 599$

\section{(c) $(1) \risingdotseq$}

Fundoscopy of right eye through dilated pupil showed Grade I media clarity and an elevated, well-defined, yellowish-gray, round-to-oval subretinal mass; $2.4 \times 1.4 \mathrm{~cm}$ in size in the lower part. Retina covering the disc and macular area in the inferior part was oedematous; retinal detachment was present with undulating movements. It was smooth, dome-shaped elevation, inferonasally suggestive of bullous retinal detachment. Fundus fluorescein angiography was not possible, because of allergic dye reaction to the patient.

\section{Ultrasonography B-Scan}

In the right eye, lens in situ with mixed echogenic domeshaped hyperechoic lesion of size $2.3 \times 1.4 \mathrm{~cm}$ was seen in posterior segment of the eye ball with fixity to the inner coats of eye ball with mild vascularity. Evidence of few fine calcific foci were seen within the lesion. Optic nerve head with retrobulbar soft tissue was normal. Features were suggestive of mixed echogenic neoclassic lesion in the posterior segment of the eye ball.

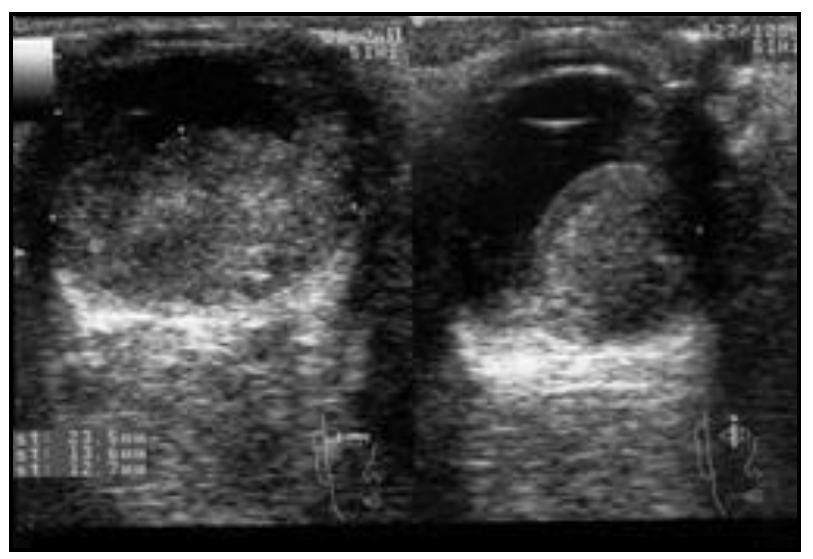

Picture 1

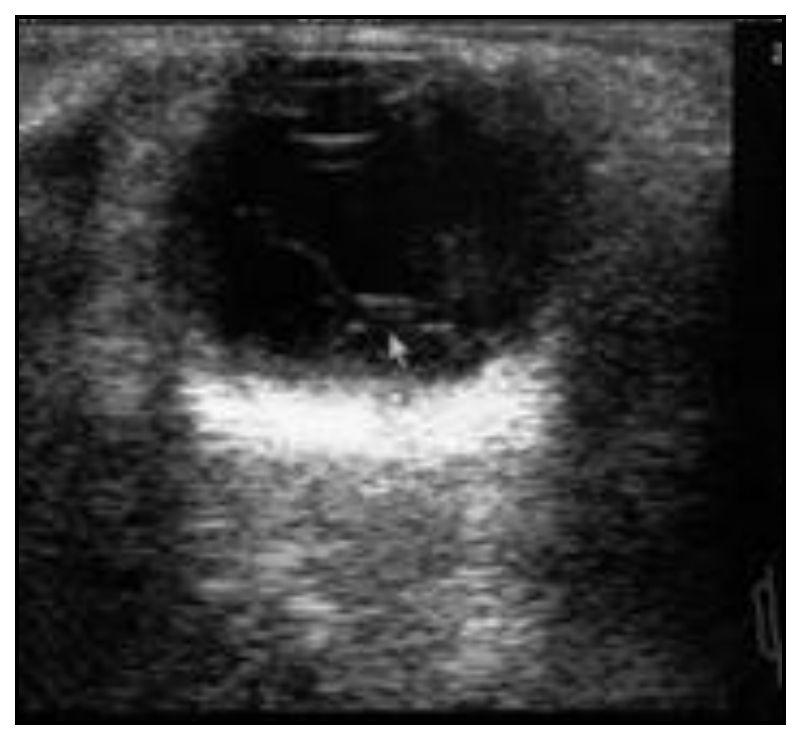

Picture 2 


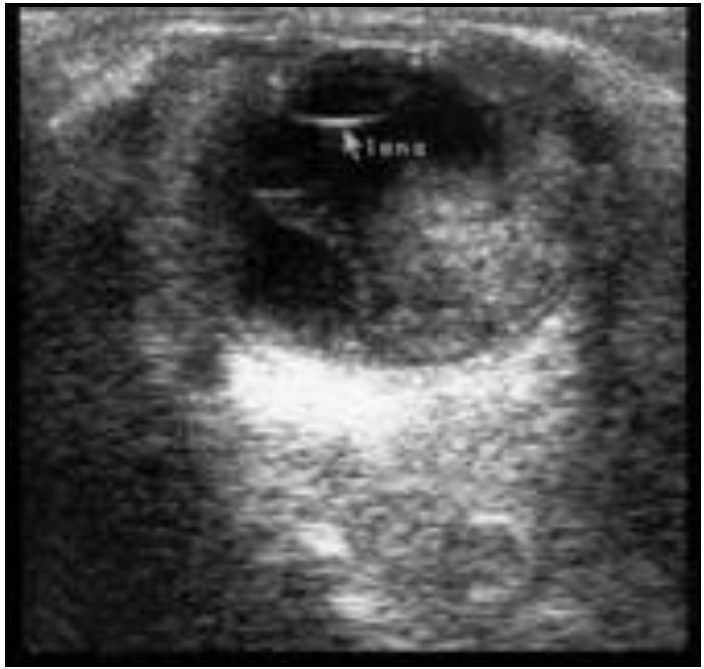

Picture 3

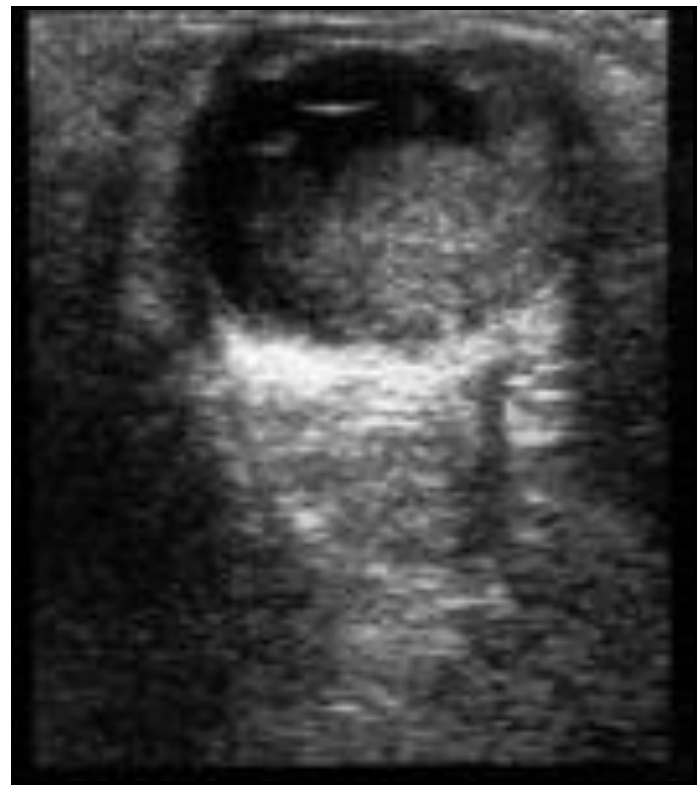

Picture 4

\section{Multislice Computed Tomography [C.T. Scan]}

Demonstrated evidence of moderately homogeneously enhancing hyperdense lesion of approximate size of $2.3 \times 1.3$ $\mathrm{cm}$ in its transverse AP and craniocaudal axis noted into vitreous chamber of right eye globe occupying almost entire posterior half. The lesion is extending in the region of optic nerve.

There was no extraocular retrobulbar extension. Extraocular muscles, optic nerve sheath complex were visualised. These parts appear normal. Left eye globe and retrobulbar structures are normal; sella and pituitary gland appear normal.

CT scan study of the orbit reveals moderately homogeneously enhancing hyperdense lesion in the vitreous chamber of right eye lesion occupying almost entire posterior half with no oblivious retrobulbar extension.

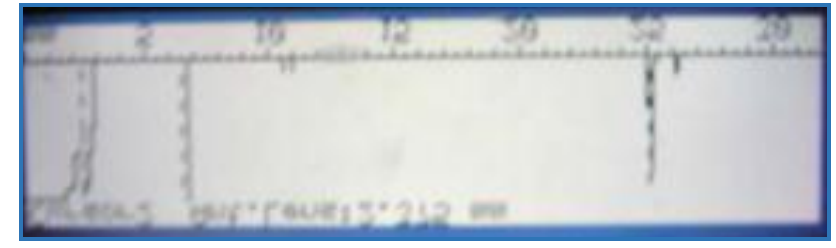

Picture 1A

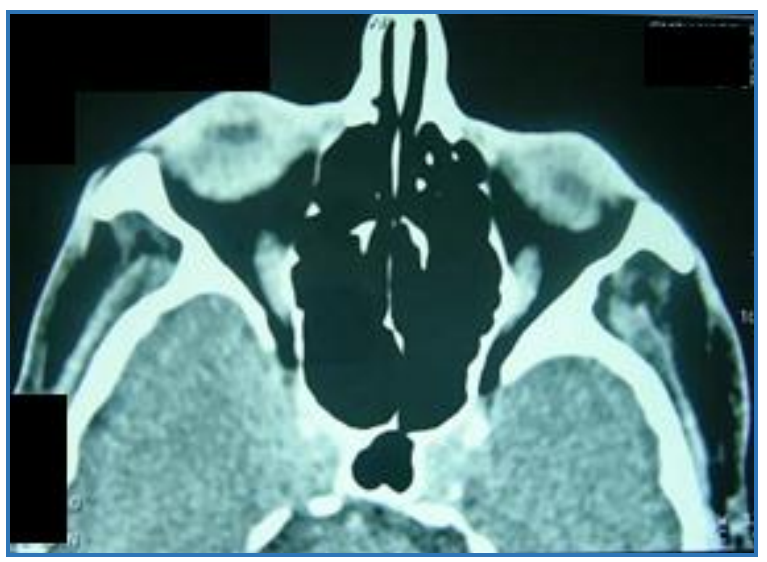

Picture 1B

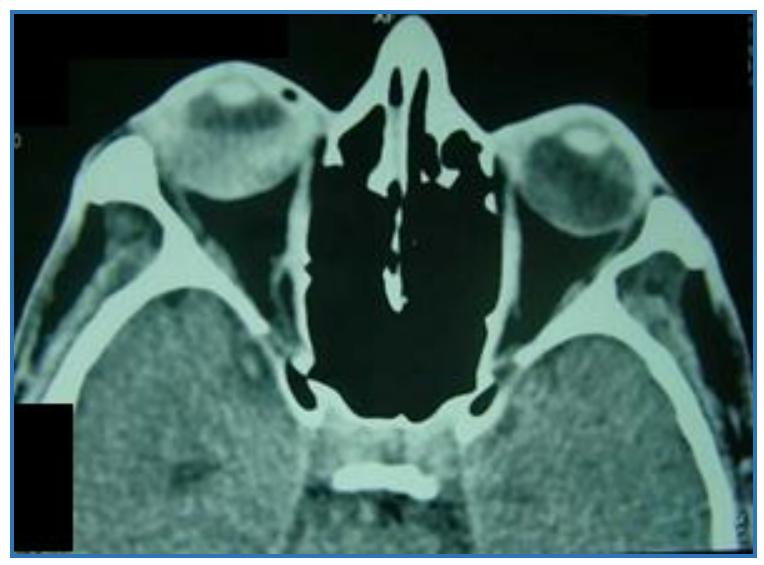

Picture 2A

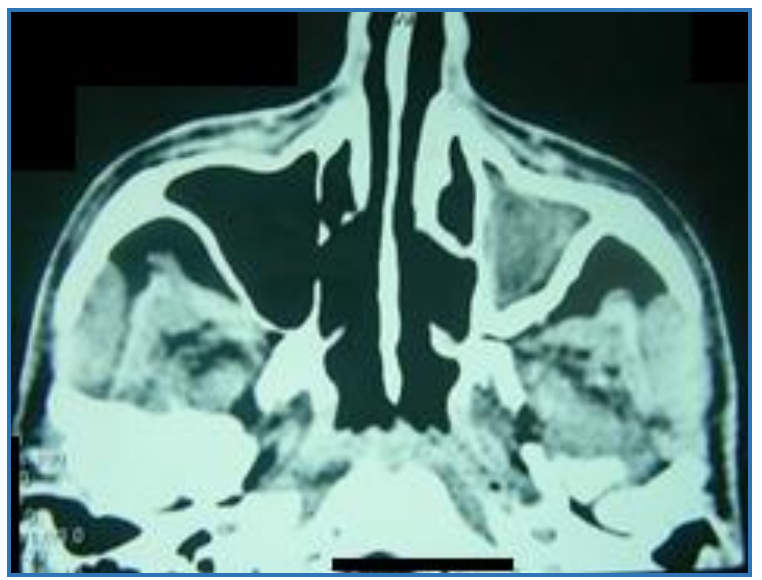

Picture 2B 


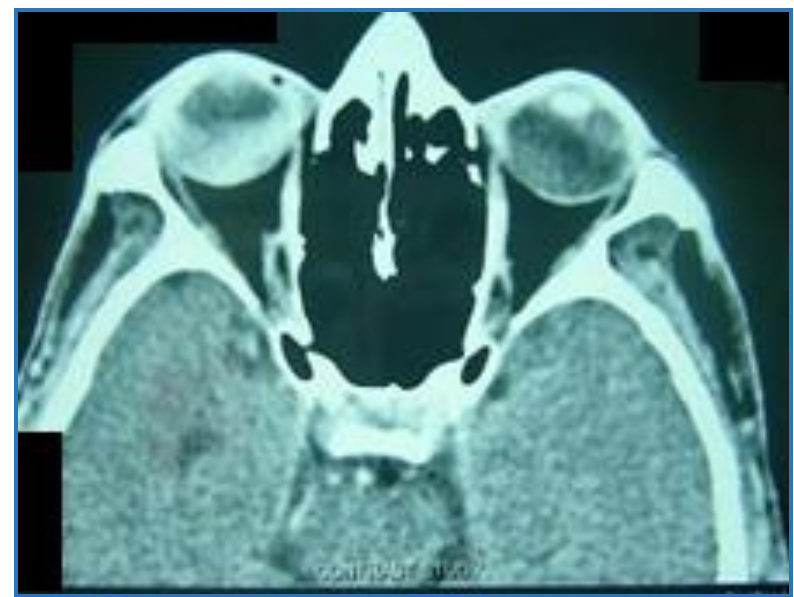

Picture 3A

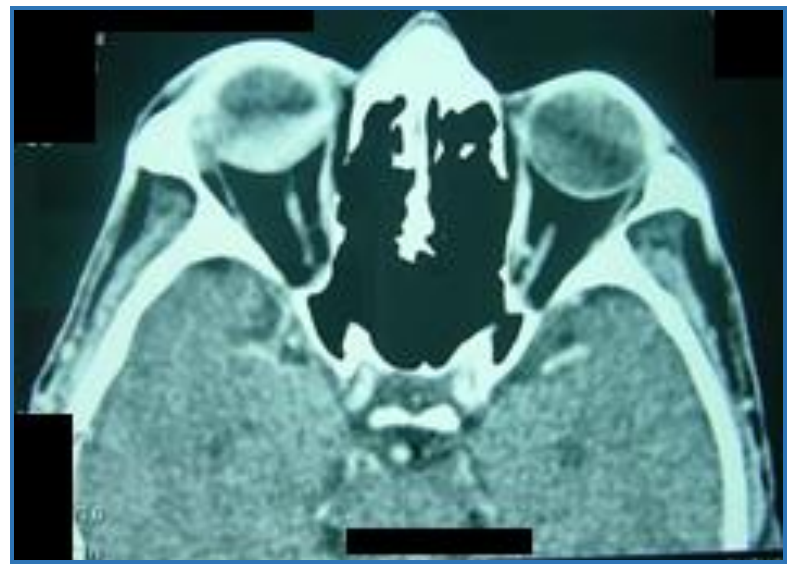

Picture 3B

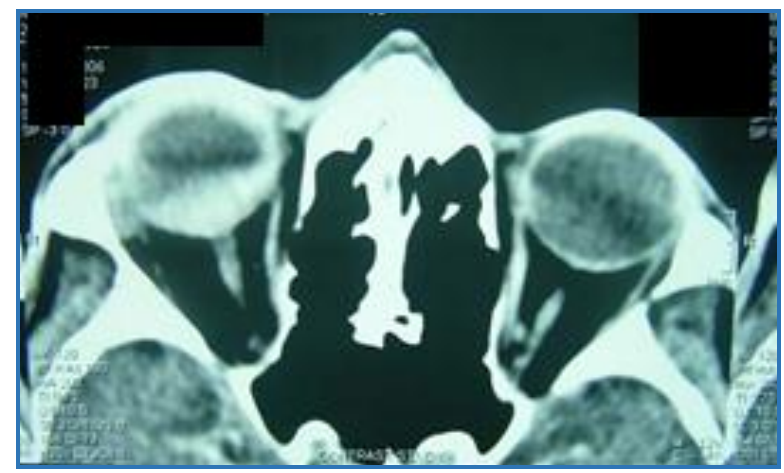

Picture 4A

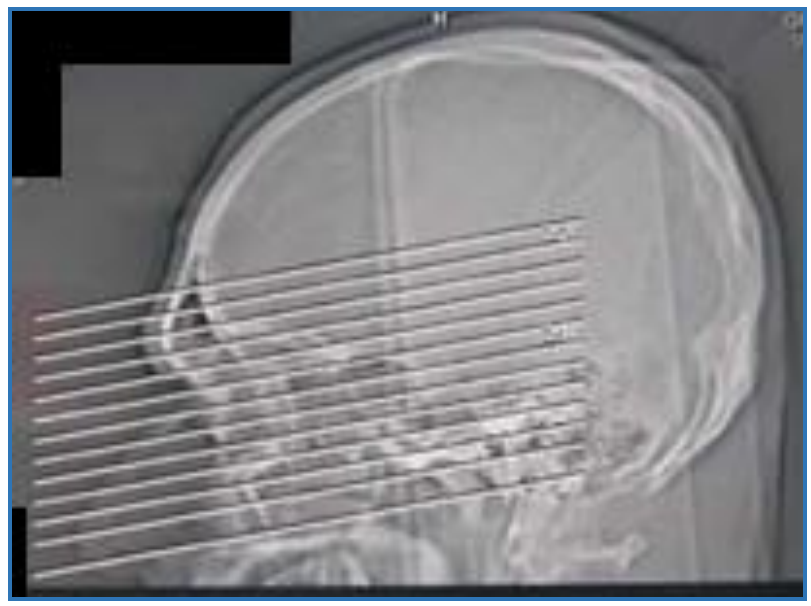

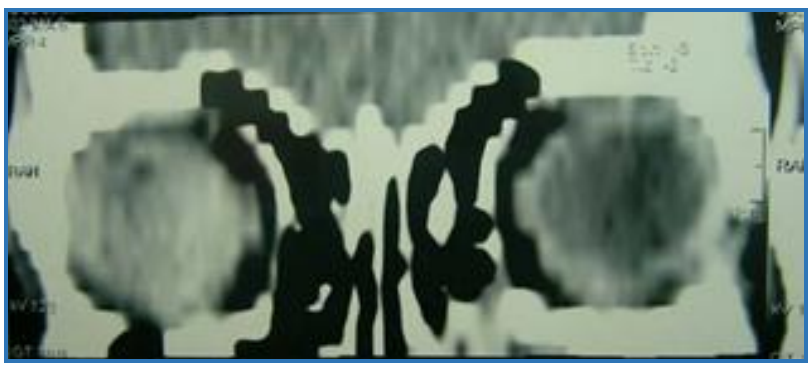

Picture 5A

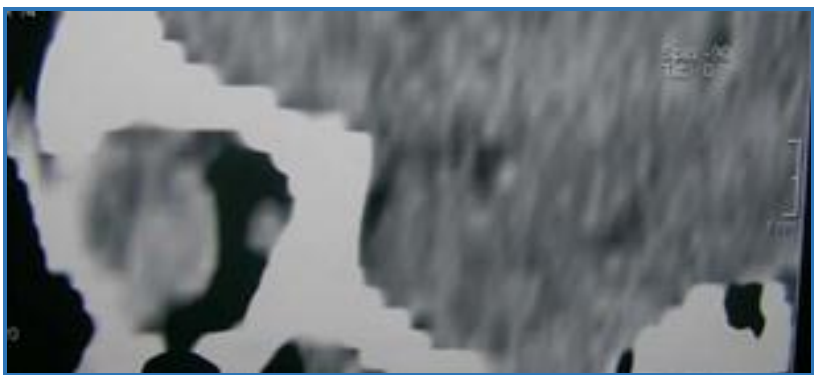

Picture 5B

Magnetic Resonance Imaging

Revealed a well-defined homogeneous lesion of approximate size of $2.3 \times 1.3 \mathrm{~cm}$ in posterior compartment of right eye globe. It is isointense to cerebellar gray matter on T1 and T2 weighted images and slightly hyperintense on proton density images. The lesion is elevating the retina anteriorly. The lesion shows T1 shortening. No extraocular spread was seen.

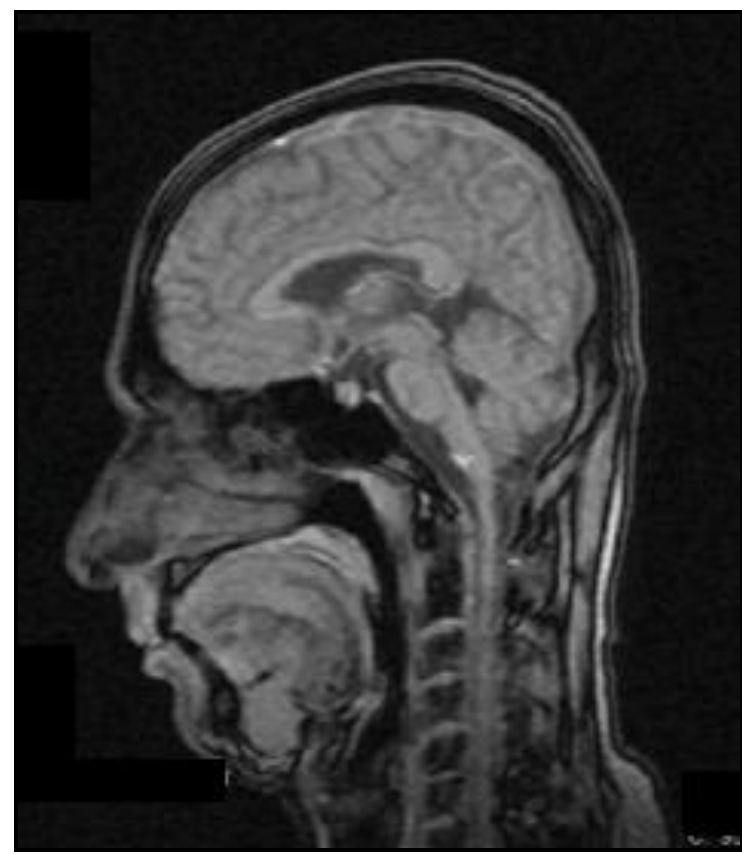

Picture 6

Picture 4B 


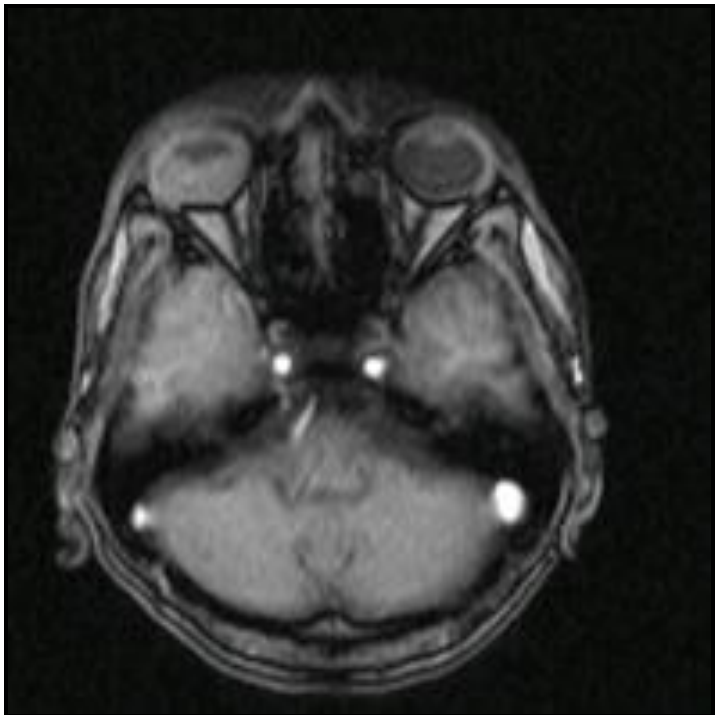

Picture 7

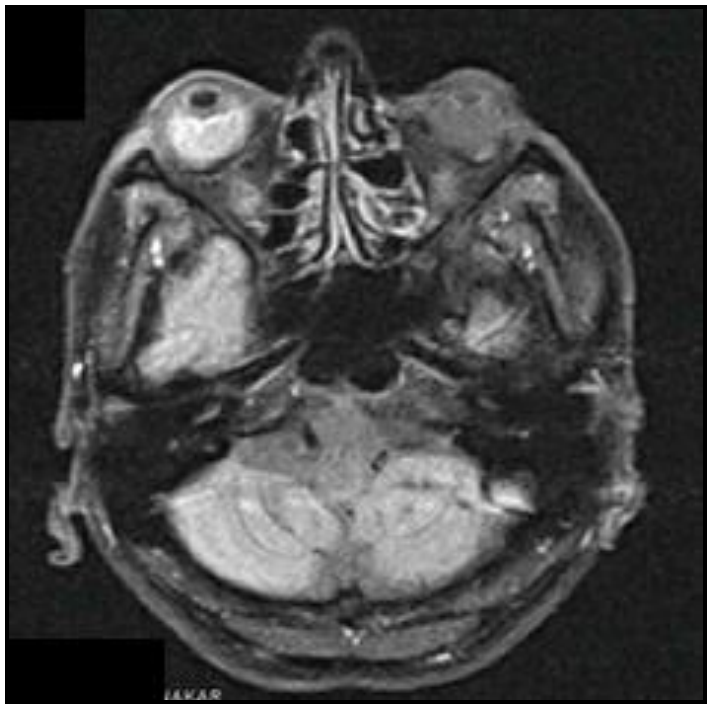

Picture 8

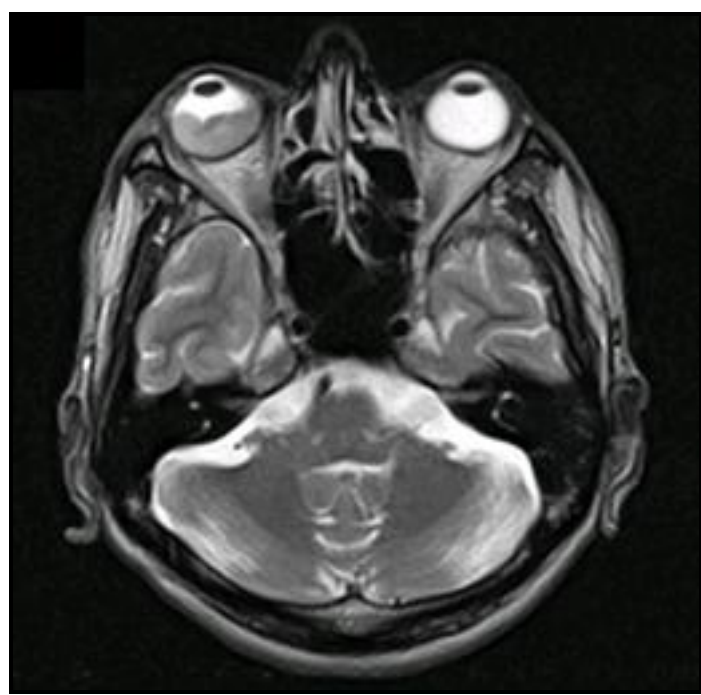

Picture 9
[S1] Section from the Optic nerve shows no Tumour Infiltrate

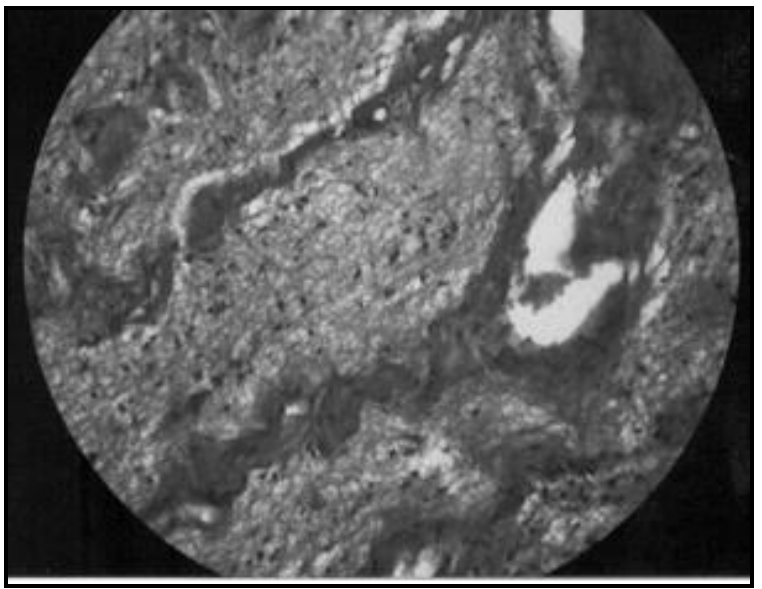

S-1

[S2 - S6] Section shows tumour mass filling the eye ball, but not infiltrating sclera. Widespread necrotic areas are seen. Tumour consists of two populations, a small cell with scanty cytoplasm, hyperchromatic nuclei arranged in sheets and spindle columnar population arranged, mostly preepithelial mitosis present. Tumour cells do not show pigment. Nucleoli are in conspicuous or absent special stain for melanin negative. This case was having diagnostic difficulty; S-100 protein and 45-immunostaining did not rule out presence of melanoma of the choroid. The confirmation of diagnosis was made as adult type malignant medulloepithelioma of ciliary body.

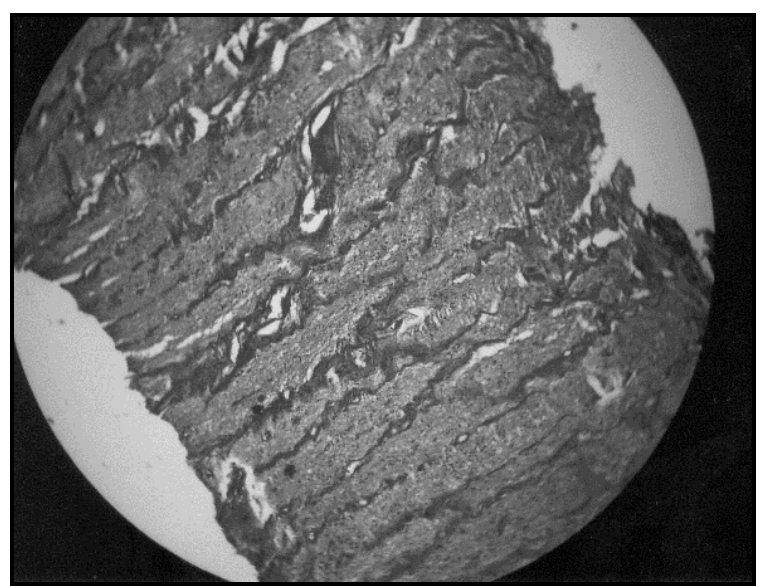

S-2

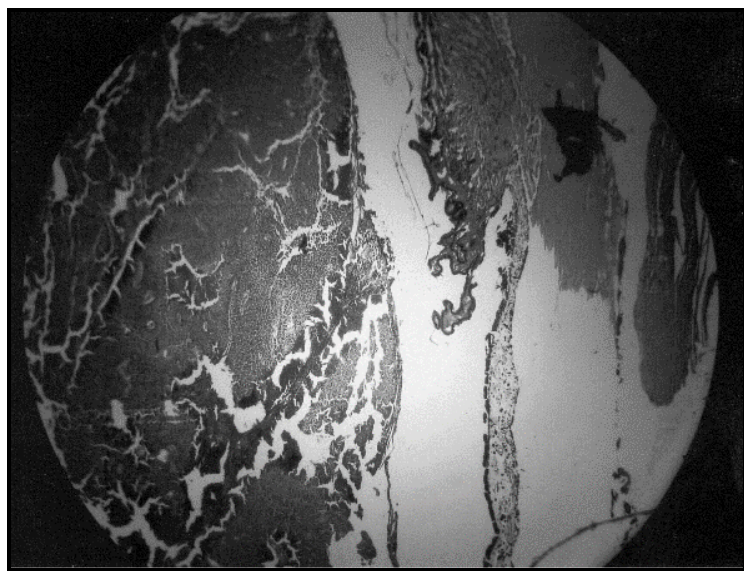

S-3 


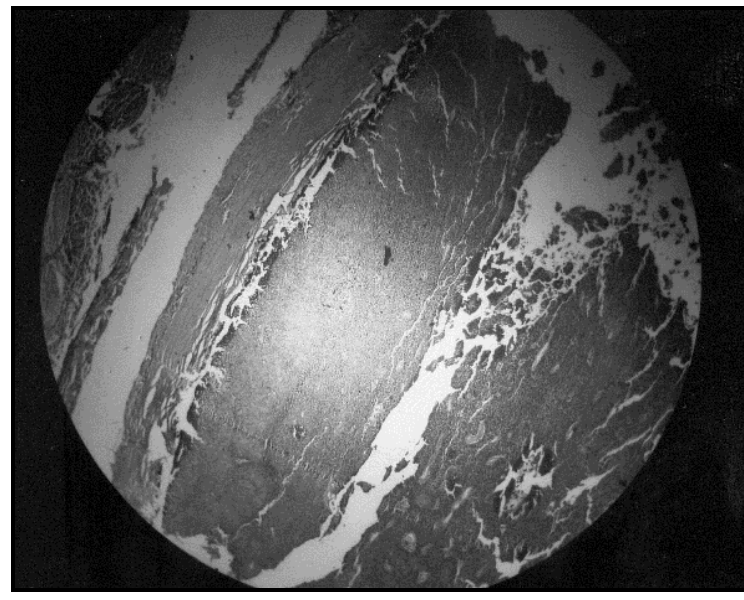

S-4

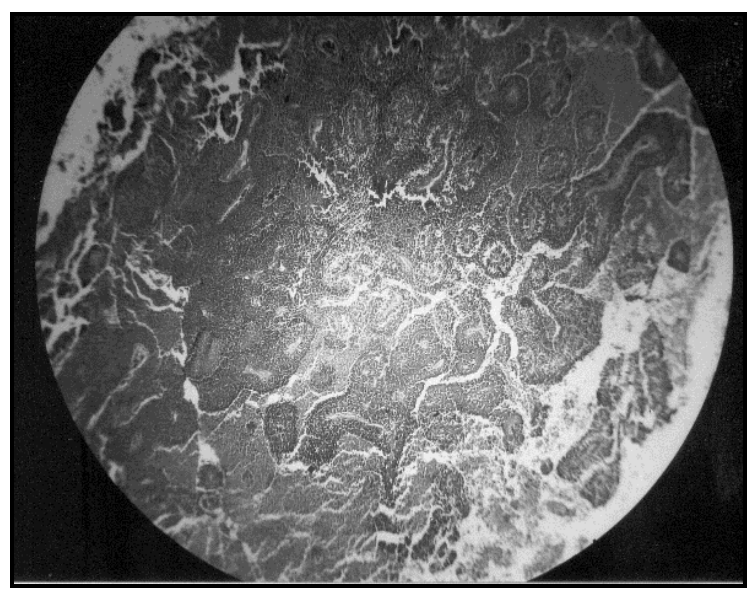

S-5

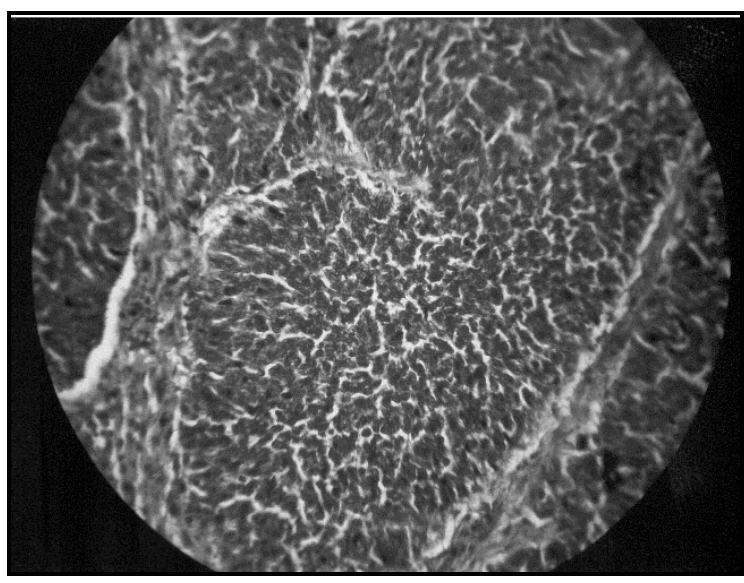

S-6

\section{DISCUSSION OF MANAGEMENT}

Malignant medulloepithelioma of ciliary body is rare in India. It is not often suspected till the tumour is large enough to cause secondary ocular changes.(1) Malignant medulloepithelioma of adult type was an unique case. Tumour arises from undifferentiated non-pigmented ciliary body epithelium. The tumour grows slowly with unilateral appearance of the tumour; distant metastasis not present. Secondary ocular changes like secondary glaucoma and retinal detachment was present. Extrascleral extension due to metastasis of the tumour was not present in this case.(2)

Ultrasonography confirms the diagnosis and location of the tumour; absence of collar-button appearance of tumour suggests that tumour confirmed to choroid and with its intact Bruch's membrane. Also, absence of pigmented cells in the vitreous cavity indicate absence of vitreous seeding. Simple classification of Zimmerman was adopted for tumours of ciliary body epithelium and divided into-

a. Congenital type- arising from undifferentiated epithelium and present commonly in childhood.

b. Adult type- arising from differentiated epithelium and present commonly in adults, undifferentiated cells do not normally persist in the ciliary epithelium into adulthood. Malignancy of the medulloepithelioma was detected by presence of poorly differentiated neuroblastic cells with extensive pleomorphism.

Optical Coherence Tomography [OCT] could highlight the changes of tumour, but OCT was not done in the present case since facility was not available.

Rarity of the tumour and difficulty in establishing the diagnosis clinically would suggest that pre-treatment tissue diagnosis would be required for proper line of approach, but in this case performance of FFA and FNAC was found to be difficult.

Enucleation should be the primary treatment for adult type of malignant medulloepithelioma. Post-operative followup was kept for two years, in which patient had heaviness and hard swelling of peanut size with chemosis in the enucleated eye after six months of operation. Radiotherapy and chemotherapy that is teletherapy was started with 23 rounds along with chemotherapy cycles, which include Inj. cyclophosphamide $750 \mathrm{mg}$, Inj. vincristine $2 \mathrm{mg}$, Inj. ondansetron $8 \mathrm{mg}$, Inj. Rantac 2 cc and Inj. Wysolone $2 \mathrm{mg}$ with continuous observation of total leucocyte count. It was observed that the tumour was sensitive to ocular teletherapy treatment.

Prognosis- As tumour was within the globe, no extrascleral extension prognosis was uniformly excellent.

\section{FINAL DIAGNOSIS}

Medulloepithelioma of ciliary body, adult type.

\section{REFERENCES}

[1] Canning CR, McCartney ACE, Hungerford J. Medulloepithelioma (diktyoma). $\mathrm{Br}$ Jor of Ophthalmoiogy 1988;72:764-7.

[2] Morris AT, Garner A. Medulloepithelioma involving the iris. Br Jor of ophthalmology 1975;59(5):276-8. 